This is the author-created draft version of Pennisi, G., Magrefi, F., Michelon, N., Bazzocchi, G., Maia, L., Orsini, F., Sanyé-Mengual, E. and Gianquinto, G. (2020). Promoting education and training in urban agriculture building on international projects at the Research Centre on Urban Environment for Agriculture and Biodiversity. Acta Hortic. 1279, 45-52 DOI: 10.17660/ActaHortic.2020.1279.7

The original publication is available at https://doi.org/10.17660/ActaHortic.2020.1279.7 


\title{
Promoting education and training in urban agriculture building on international projects at the Research Centre on Urban Environment for Agriculture and Biodiversity.
}

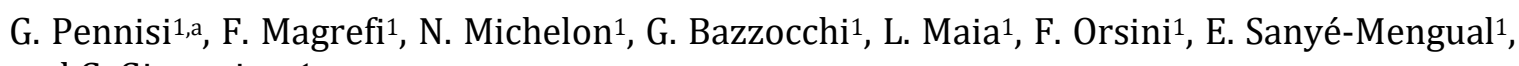
and G. Gianquinto ${ }^{1}$

${ }^{1}$ RESearch Centre on Urban Environment on Agriculture and Biodiversity (RESCUE-AB), University of Bologna, Italy

\begin{abstract}
The RESearch Centre on Urban Environment for Agriculture and Biodiversity (RESCUE-AB), within the Department of Agricultural and Food Sciences of the University of Bologna, is committed to promote urban horticulture and biodiversity in Europe and in several countries of the Global South, bringing together skills and research expertise in the fields of horticulture, environmental sciences and entomology. Educational activities build upon a range of international projects, specifically devoted to create innovative training tools. These range from adult education for urban gardeners and school educators, to higher education curricula. Lifelong learning instruments addressing the social and environmental functions of urban horticulture have been developed within the framework of LLP-Grundtvig projects, such as the project "HORTIS" (Horticulture in Towns for Social Inclusion and Socialisation, www.hortis-europe.net). Successful application of the developed educational models are already being explored within social projects, such as the Urban Innovative Action "SALUS W SPACE" (Villa SALUS as a new Sustainable Accessible Livable Usable Social space for intercultural Wellbeing, Welfare and Welcoming in the Metropolitan City of Bologna), in which urban agriculture becomes a tool for social inclusion and capacity building among communities of political refugees and immigrants. Specific training on how to design and implement educational gardens in schools is then the main objective of the ongoing project "GARDENS TO GROW" (Urban Horticulture for Innovative and Inclusive Early Childhood Education), funded by Erasmus+. The same funding scheme promoted between 2014 and 2017 the project "URBAN GREEN TRAIN" (URBAN GReen Education for ENTteRprising Agricultural Innovation), with the aim of encouraging the creation of pioneering business initiatives in Urban Agriculture (UA), by reinforcing the so called knowledge triangle among Education, Research and Business. Within the project a partnership of public and private organizations from Italy, France, Germany and The Netherlands, developed, tested and made available to different types of learners a pilot international, crosssectoral, multi-targeted training path on Urban Agriculture Entrepreneurship. Similarly, the ongoing project Erasmus+ "BUGI" (Western Balkans Urban Agriculture Initiative) brings together the most innovative business models in urban agriculture in Europe and support their adaptation and diffusion in Eastern Europe and the Balkan context. Finally, the capacity-building of early-stage researchers was addressed in the project H2020 MSCA "SUSTURBANFOODS" (Integrated sustainability assessment of social and technological innovations towards urban food systems), where innovative research on comparative sustainability assessment of different urban horticulture models across Europe was set in place.
\end{abstract}

aE-mail: giuseppina.pennisi@unibo.it 
Keywords: Urban Agriculture; Entrepreneurship; Education; Training

\section{INTRODUCTION}

Allotment gardens, urban farms, school gardens, green enterprises and many other initiatives covering the so-called "farm to fork" linkages are growing all over EU, to meet the global demand for urban green innovation (Deeslstra and Girardet, 2007; Blair, 2009). Strengthening the knowledge triangle and reinforcing the cooperation among Education, Research and Business is key to train the European human capital with the right mix of expertise and competences that are required by the knowledge society for a sustainable growth (Magrefi et al., in press). The RESearch Centre on Urban Environment for Agriculture and Biodiversity (RESCUE-AB) has coordinated and participated in a number of educational EU projects aimed at generating and transferring knowledge in the field of multifunctional urban agriculture (UA) with a special attention on the three spheres of sustainability: social, economic and environmental.

In this paper, a combined methodology for the creation of innovative educational tools on urban agriculture is elaborated, addressing the main questions to be solved in order to promote efficient and sustainable UA systems.

\section{METHODS}

The study builds on the experience created along 6 European projects on education in UA in which RESCUE-AB participated in the last years (Table 1). Each of these projects targeted different end users, therefore the developed educational material was adapted to the diverse training needs.

\begin{tabular}{|c|c|c|c|c|c|c|}
\hline EU Project & Users & $\begin{array}{c}\text { Teachers } \\
\text { trained }\end{array}$ & $\begin{array}{l}\text { Users } \\
\text { trained }\end{array}$ & $\begin{array}{l}\text { Hour } \\
\text { load }\end{array}$ & ECTS & Period \\
\hline HORTIS & Adults & 110 & 280 & 60 & 2 & $\begin{array}{l}2012- \\
2014\end{array}$ \\
\hline SalusWSpace & Refugees & 6 & 14 & 180 & - & $\begin{array}{l}2017- \\
2020\end{array}$ \\
\hline GardensToGrow & School managers and teachers & 750 & 720 & 90 & - & $\begin{array}{l}2017- \\
2019\end{array}$ \\
\hline UrbanGreenTrain & MSc students, professionals & 20 & 120 & 150 & 5 & $\begin{array}{l}2014- \\
2017\end{array}$ \\
\hline BUGI & MSc students & 50 & 200 & 3000 & 120 & $\begin{array}{l}2017- \\
2020\end{array}$ \\
\hline SustUrbanFoods & Early Stage Researchers & - & 1 & 3000 & - & $\begin{array}{l}2016- \\
2018\end{array}$ \\
\hline
\end{tabular}

In the following sessions, the methodology used for designing the course curricula addressing societal needs will described and analyzed.

\section{RESULTS AND DISCUSSION}

The considered EU projects are distributed in several European countries, spanning from the Mediterranean region (e.g. Italy, Spain), Central and Northern Europe (e.g. France, Germany, The Netherlands, Slovenia and United Kingdom), and Eastern Europe and the Balkans (e.g. Hungary, Kosovo, Montenegro, Bosnia and Herzegovina) (Figure 1). Coherently with the user typology targeted in each project and the learning outcomes addressed, different educational tools were also developed (Figure 1). 


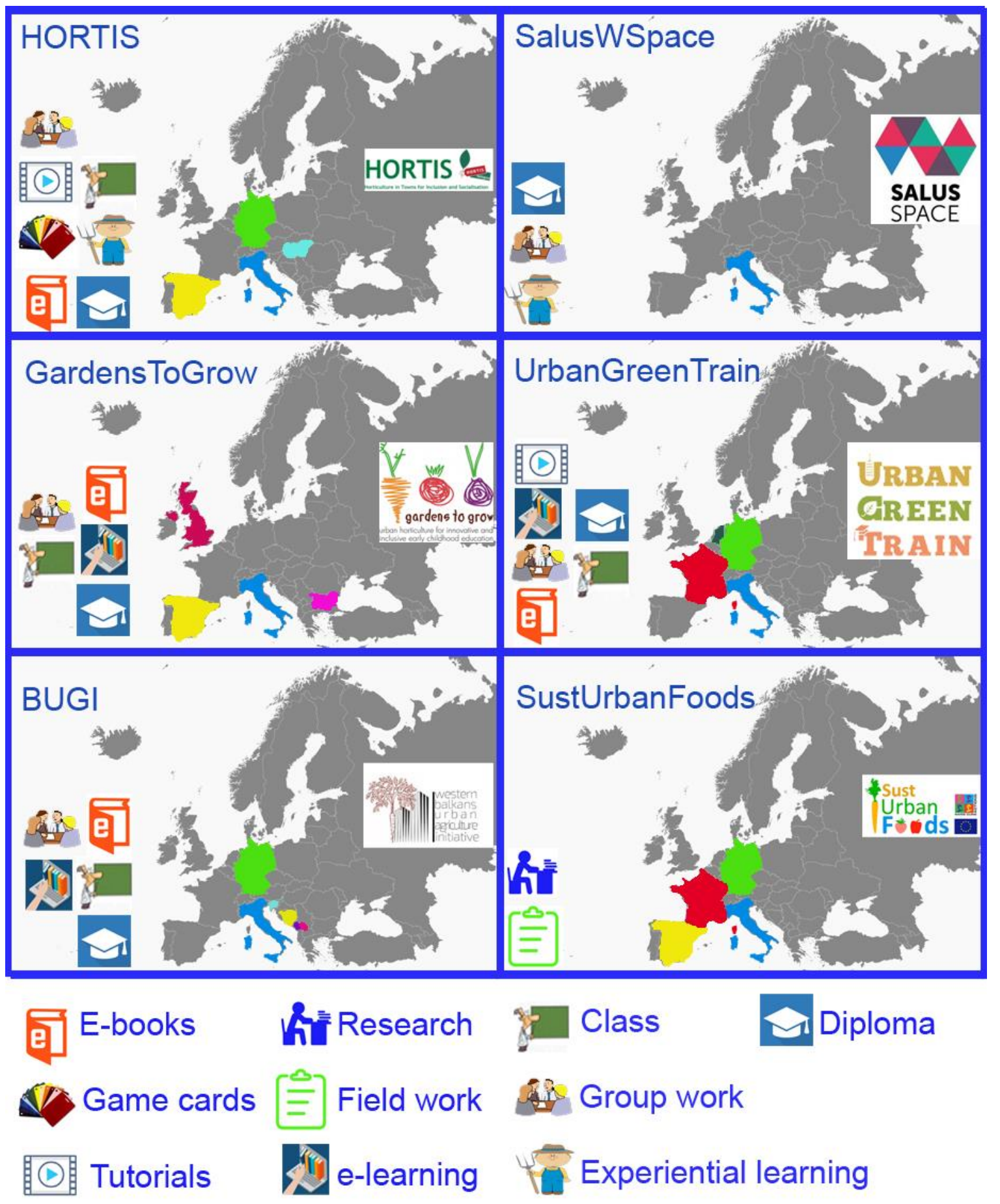

Figure 1. Regional distribution and educational tools adopted in the projects presented in this study. 


\section{ADULT EDUCATION AND SOCIAL INCLUSION THROUGH INFORMAL STUDY CURRICULA}

Urban gardens have many different and important functions beside food production, including social, educational and therapeutic ones. UA was extensively practiced during the '70 and ' 80 and, after a period of shade in the ' 90 , recently restarted to grow also associated with the precarious income and underfeeding conditions of a large portion of the urban population (Ho-Fei et al., 2014). Social and therapeutic functions of urban horticulture are nowadays widely recognized and used, in particular for the support and rehabilitation of disadvantaged persons. Concurrently, the educational role of horticulture also among adults is widely recognized (Bowker and Tearle, 2007, Rye et al., 2012). The European project HORTIS: HORticulture in Towns for Inclusion and Socialisation (526476-LLP-1-2012-1-IT-. GRUNDTVIG-GMP https://site.unibo.it/hortis/en) - funded by the European Union in the framework of the Lifelong Learning Programme - Grundtvig sub-programme - groups together experiences of urban community gardens all over Europe for the implementation of innovative methodologies and training tools to foster the acquisition of key competences for lifelong learning. The positive effects of practical urban gardening activities resulted in enhancing social cohesion and mutual help, in increasing the sense of belonging to the community and self-esteem, thus encouraging acquisition of transversal key competences. The project developed a set of high-quality educational materials combining food selfproduction techniques with informal teaching approaches. The acquisition of new skills was addressed by combining learning to learn, spirit of entrepreneurship and civil and social competences (Magrefi et al., 2014).

Successful application of the developed educational models are already being explored within social projects, such as the Urban Innovative Action "SALUS W SPACE" (Villa SALUS as a new Sustainable Accessible Livable Usable Social space for intercultural Wellbeing, Welfare and Welcoming in the Metropolitan City of Bologna, UIA-01-047 http://saluspace.eu), in which UA becomes a tool for social inclusion and capacity building among communities of political refugees and immigrants. The overall objective of the three years project is to build a center for hospitality and introduction into the job market, combined with activities in the fields of intercultural welfare and wellness (Salus Space). This will be addressed by creating an experimental site for social innovation through a participatory design process (co-design), with a generative and intercultural welfare approach. Based on this pilot project, an innovative and replicable model of reception and integration for refugees is being developed, adaptable to the different contexts. In the premises of the Salus Space, vegetable gardens will be designed for not only giving value to the surrounding green spaces, but also offering opportunities to the users to learn about biodiversity and urban ecology, to cultivate, to meet and socialize, as well as to set up new forms of business, thereby producing income. Accordingly, the involved actors will co-design three main garden typologies, one focused on food production, another mainly used for training and an inclusive garden, where social inclusion and welcoming practices will be promoted through intercultural exchanges. The creation of gardens will be accompanied by an experiential training course, which will involve both the local and migrant communities, also with the aim of creating new entrepreneurial opportunities for the most disadvantaged (e.g. in gardening or landscaping services or even starting a UA business on their own). Specific training tools are being developed (over a total load of 180 hours), mainly using learning-by-doing approaches. In the project, coordinated by Bologna City Council, the role of RESCUE-AB is to contribute in the garden design and the implementation of the training activities.

\section{A GARDEN TO GROW: URBAN AGRICULTURE IN THE CONTEXT OF EARLY CHILDHOOD EDUCATION}

In the urbanization era, a concurrent loss of the traditional agricultural knowledge is emerging (McClintock, 2010), also resulting in depleted dietary regimes, especially among children (Pérez-Lizaur et al., 2008). In recent years, particular attentions have been invested in hands-on programming-such as cooking activities, farm-to-school, and gardening actions - to connect children with fresh and healthy foods. As reported in Roche et al, (2017), the most promising approaches may combine curricular learning with hands-on experiences. 
School gardening has shown to foster improved nutrition among the youth (Alaimo, 2008), also becoming an instrument to combat childhood obesity (Roche et al., 2017). Beside improved food behavior, gardening during early childhood was shown to provide a number of other functions, including science achievement as well as positive social and environmental attitudes (Blair, 2009).

The project GARDENStoGROW: Urban Horticulture for Innovative and Inclusive Early Childhood Education is co-funded by the EU Erasmus+ program (2017-1-IT02-KA201036449, http://www.gardenstogrow.eu/). The main goal is to create educational and inclusive gardens as well as training courses for early childhood teachers and school managers towards developing basic, civic and transversal skills for the 3-5 age group. In each of the partner institutions in Italy, United Kingdom, Spain and Bulgaria, surveys among schools that already had a garden in the ground will be realized in order to highlight strengths and weaknesses of gardening activities from a technical and social point of view. A guide on how to build an educational and inclusive school gardens will be produced to encourage more schools starting with outdoor activities. In each of the partner institutions educational gardens will be installed as spaces for meetings, exchanges and learning for children, teachers and families. Started in September 2017, the project will last until February 2020. The project, coordinated by Explora, the children's museum of Rome, counts on RESCUE-AB as partner with specific tasks on the development of the educational tools.

\section{URBAN AGRICULTURE IN THE CONTEXT OF HIGHER EDUCATION.}

Along with the increased interest in UA activities and the blooming of related entrepreneurial experiences, the need for appropriate training tools also within the higher education system has emerged. Most of the entrepreneurs entering the sector have limited farming background and come from other professional experiences (Deelstra and Girardet, 2000). However, for urban farms to be competitive with the commercial agricultural sector, state-of-the-art farming techniques need to be set in place. Interdisciplinary knowledge (e.g. providing also skills in engineering, architecture, management and finance and social sciences) is crucial in order to adapt the growing systems to advantages and constrains associated with plant cultivation in the urban environment (Hoi-Fei et al., 2014).

The EU-funded ERASMUS+ strategic partnership in Higher Education project called URBAN GREEN TRAIN: URBAN GReen Education for ENTteRprising Agricultural INnovation (2014-1-IT02-KA200-003689, https://site.unibo.it/urbangreentrain/en) aimed to develop, test and make available to different types of learners a pilot international, cross-sectoral, multi-targeted training path on Urban Agriculture Entrepreneurship, and a dedicated set of educational resources and materials (Magrefi et al., in press). The three-years project was coordinated by RESCUE-AB and included partners from Italy, Germany, France and The Netherlands, and ended in August 2017. It resulted in the completion of a database of the innovative UA enterprises and existing educational resources across Europe and in the creation of an interdisciplinary curriculum on entrepreneurial UA. The resulting course adopted a blended learning modality (grouping face-to-face and distance learning modules), and resulted in a 150 hours load. It was awarded by 5 ECTS inside existing master curricula at the University of Bologna (Italy) and the South-Westphalia University of Applied Sciences (Germany). The course (whose contents are also available online on the project website) was structured into an introduction to UA, the valorization of urban resource use in UA systems, a description of established and innovative typologies of UA and specific skills on social networking and business management. About 120 international students attended the pilot course, which also included a 2-week winter school at the University of Bologna in 2017. Along the course, feedbacks from tutors and students were integrated in order to finalize the curriculum and generate a comprehensive competence framework in UA entrepreneurship (Bagigalupo et al., 2016), including components in terms of knowledge, skills and attitudes. The project succeeded in giving a significant overview of the relevant state of art on entrepreneurship, educational offer and training needs in UA and provided an adequate basis for developing relevant training modules and educational resources supporting new entrepreneurship. 
Grounding on the innovative educational tools developed within URBAN GREEN TRAIN and the limited number of UA experiences in Eastern European countries, the project BUGI: Western Balkans Urban Agriculture Initiative (586304-EPP-1-2017-1-BA-EPPKA2-CBHE-JP, http://bugi.unsa.ba/) was started in 2017. Within the project, coordinated by the University of Sarajevo (Bosnia and Herzegovina), the role of RESCUE-AB stands in the definition of the structure of a Master degree on UA (120 ECTS) and in supporting the implementation of an inventory of innovative UA business experiences in the Balkan countries. Within the three years of the action, partners in Bosnia and Herzegovina, Montenegro, Kosovo, Italy, Germany and Slovenia will actively contribute to the organization of 6 study visits, 2 workshops and a pilot Master Course involving 50 teachers and 200 students (Table 1).

\section{FOSTERING INNOVATIVE RESEARCH IN UA}

Given the growing role of UA projects and experiences, research needs to evolve, elaborating new methodologies to adapt available knowledge in social, agricultural, engineering and environmental sciences to this emerging sector. For instance, plant cultivation inside cities has often been promoted as a sustainability model based on the reduced impact of the food production, processing and delivery processes. Nevertheless, literature on comparative life cycle analyses of rural vs urban food production is only recent. The environmental assessment of rooftop greenhouse (Sanyé-Mengual et al., 2015a) plant cultivation has resulted in the identification of main impacting stages being associated with post-harvest packaging and transport of horticultural goods. However, inefficiencies in urban growing systems were also observed, e.g. with reference to the use of drinkable tap water for irrigation (Sanyé-Mengual et al., 2015b), or the limited radiation use efficiency when a building-integrated greenhouse is compared with a rural one (Nadal et al., 2017). The energetic and financial sustainability of urban indoor plant cultivation in Plant Factories with Artificial Lighting (PFALs) was also questioned, by comparing PFALs against commercial greenhouses located in three different climates, namely a greenhouse with supplemental lighting in Sweden, a Venlo greenhouse in The Netherlands and a semi-closed greenhouse in United Arab Emirates (Graamans et al., 2018). Beside the environmental and technological aspects, however, UA projects should also be addressed for their financial and social sustainability. Integrating an analysis of the three spheres of sustainability in existing UA projects was the aim of the EU action SustUrbanFoods (H2020-MSCA-IF-2015-708672, https://susturbanfoods.com/). The project, coordinated by the RESCUE-AB, resulted in a sustainability assessment and ranking of 11 innovative UA projects from Italy, Spain, France and Germany. The method was developed through a participatory research design process where stakeholders contributed with their knowledge and perceptions via two workshops. As a first step, a comprehensive definition of the concepts around the sustainability of urban food production was set (Sanyé-Mengual et al., 2018). Results were gathered from the field data collection and interviews with key informants (e.g. managers, gardeners).

\section{CONCLUSIONS}

In the present work, several of the most effective efforts toward the creation of educational instruments to foster sustainable plant cultivation in cities were described. Depending on the addressed user typology, different tools were adopted, including distance and blended learning techniques, hands-on training, or the use of innovative media supports (e.g. video, e-books, game cards) and participatory practices (experiential learning, citizen science and icebreakers/games). More than 900 teachers were trained all over Europe and above 1300 users had the chance to attend pilot courses on UA during the projects lifespan. The created curricula were often integrated into the higher education system, enabling enrolled students in partner universities to have recognized ECTS upon their attendance to the developed courses. The availability of dedicated EU funding programs enabled to integrate international expertise from higher education institutions, the private sector and no-profit organizations, resulting in the creation of comprehensive materials tailored to the specific user-needs. Furthermore, it contributed in fostering the knowledge and awareness 
on UA across Europe, given that all created materials are publicly available within the dedicated project websites.

\section{Acknowledgements}

The present work was co-funded by European projects within the calls:

- Erasmus+: GardensToGrow (2017-1-IT02-KA201-036449) and BUGI (586304-EPP-12017-1-BA-EPPKA2-CBHE-JP).

- Urban Innovative actions: SalusWSpace (UIA-01-047).

\section{Literature Cited}

Alaimo, K., Packnett, E., Miles, R. A., \& Kruger, D. J. (2008). Fruit and vegetable intake among urban community gardeners. J. Nutr. Educ Behav., 40: 94-101.

Bacigalupo, M., Kampylis, P., Punie, Y., and Van den Brande, G. (2016). EntreComp: The Entrepreneur-ship Competence Framework (Luxembourg: Publication Office of the European Union) http://doi.org/10.2791/593884.

Blair, D. (2009). The child in the garden: An evaluative review of the benefits of school gardening. The Journal of Environ. Educ., 40: 15-38.

Bowker, R., and Tearle, P. (2007). Gardening as a learning environment: A study of children's perceptions and understanding of school gardens as part of an international project. Learn. Environ. Res., 10: 83-100.

Deelstra, T., \& Girardet, H. (2000). Urban agriculture and sustainable cities. Bakker N., Dubbeling M., Gündel S., Sabel-Koshella U., de Zeeuw H. Growing cities, growing food. Urban agriculture on the policy agenda. Feldafing, Germany: Zentralstelle für Ernährung und Landwirtschaft (ZEL), 43-66.

Graamans, L., Baeza, E., Van Den Dobbelsteen, A., Tsafaras, I., \& Stanghellini, C. (2018). Plant factories versus greenhouses: Comparison of resource use efficiency. Agricult. Syst., 160: 31-43.

Hoi-Fei, M., Williamson, V.G., Grove, J.R., Burry, K., Barker, S.F., and Hamilton, A.J. (2014). Strawberry fields forever? Urban agriculture in developed countries: a review. Agron. Sust. Dev., 34: 21-43.

Magrefi, F., Orsini, F., Bazzocchi, G., \& Gianquinto, G. (2014). Learning through gardening: The HORTIS experience. In EDULEARN14 Proceedings (pp. 5366-5374). IATED.

Magrefi, F., Geoffriau, E., Kahane, R. Pölling, B., Orsini, F., Pennisi, G., Bazzocchi, G., Renting, H., Hoekstra, F., Morgenstern, R., Dubbeling, M., Lorleberg, W., and Gianquinto, G. (in press). Training pioneering entrepreneurs in Urban Agriculture: a model of curriculum based on the URBAN GREEN TRAIN project experience. In Proceedings of the International Symposium on Greener Cities for More Efficient Ecosystem Services in a Climate Changing World (Bologna, 2017). Acta Hortic.

McClintock, N. (2010). Why farm the city? Theorizing urban agriculture through a lens of metabolic rift. Cambridge J. Regions, Econ. Soc., 3: 191-207.

Nadal, A., Llorach-Massana, P., Cuerva, E., López-Capel, E., Montero, J. I., Josa, A., ... \& Royapoor, M. (2017). Buildingintegrated rooftop greenhouses: An energy and environmental assessment in the mediterranean context. Appl. Ener., 187: 338-351.

Pérez-Lizaur, A. B., Kaufer-Horwitz, M., \& Plazas, M. (2008). Environmental and personal correlates of fruit and vegetable consumption in low income, urban Mexican children. J. Hum. Nutr. Dietet., 21: 63-71.

Roche, E., Kolodinsky, J. M., Johnson, R. K., Pharis, M., \& Banning, J. (2017). School Gardens May Combat Childhood Obesity. Choices, 32: 1-6. 
Rye, J. A., Selmer, S. J., Pennington, S., Vanhorn, L., Fox, S., \& Kane, S. (2012). Elementary school garden programs enhance science education for all learners. Teach. Except. Child., 44: 58-65.

Sanyé-Mengual, E., Oliver-Solà, J., Montero, J. I., \& Rieradevall, J. (2015a). An environmental and economic life cycle assessment of rooftop greenhouse (RTG) implementation in Barcelona, Spain. Assessing new forms of urban agriculture from the greenhouse structure to the final product level. Int J. Life. Cyc. Assess., 20: 350-366.

Sanyé-Mengual, E., Orsini, F., Oliver-Solà, J., Rieradevall, J., Montero, J. I., \& Gianquinto, G. (2015b). Techniques and crops for efficient rooftop gardens in Bologna, Italy. Agr. Sust. Dev.,, 35:1477-1488.

Sanyé-Mengual, E., Orsini, F., \& Gianquinto, G. (2018). Revisiting the Sustainability Concept of Urban Food Production from a Stakeholders' Perspective. Sustainability (2071-1050),10(7). 